\title{
Diluting education? An ethnographic study of change in an Australian Ministry of Education
}

\author{
Sarah Robinson* \\ The University of Western Australia
}

\begin{abstract}
This ethnographic study captures the processes that led to change in an Australian public education system. The changes were driven by strong neo-liberal discourses which resulted in a shift from a shared understanding about leading educational change in schools by knowledge transfer to managing educational change as a process, in other words, allowing the schools to decide how to change. Inside an Australian state education bureaucracy at a time when the organisation was restructured and services decentralised, this study helps show some of the disturbing trends resulting from the further entrenchment of neo-liberal strategies. Although control was re-centralised by legitimising performance mechanisms, in the form of national testing, there are indications that the focus on national tests may have alarming consequences for the content and context of education. I argue that the complexities of learning and fundamental pedagogies are being lost in preference for an over-reliance on data systems that are based on a shallow and narrow set of standardised measures.
\end{abstract}

Key words: neo-liberalism; bureaucracy; testing; decentralisation; learning; pedagogy

\section{Introduction}

Australia comprises of six states and two territories that are constitutionally responsible for education. To protect the identity of the organisation being discussed in this study, and the people working in it, I endeavour to describe it in general terms, and use pseudonyms for the people. This ethnographic study captures the processes that led to change in an Australian State education system. The study illustrates neo-liberalism in practice. The changes were driven by strong neo-liberal discourses which resulted in a shift from a bureaucratic organisation which valued professionalism and expertise to one that placed values on managerialism and performance technologies. The ideological agenda driving public systems towards marketisation and a focus on the economy have been commented upon by many scholars (Clarke \& Newman, 1997; du Gay, 2005; Marquand, 2004; Miller \& Rose, 2008; Osborne \& Gaebler, 1993).

\footnotetext{
* School of Education The University of Stirling Stirling FK9 4LA UK Email: $\underline{\text { sarah@ sarahrobinson.dk }}$
} 
Since the 1980s, the focus on the efficiency of public systems has resulted in restructuring, redesigning and paring down of some of these bureaucratic organisations (Ozga, 2009). Education has become a site of investment for the state that seeks a competitive position in global markets (Apple, 2001). Inside an Australian state education bureaucracy at a time when the organisation was restructured and services decentralised, this study helps show some of the disturbing trends resulting from the further entrenchment of neo-liberal strategies. Much has been written about the effects of neoliberalism in education over the last decade (Apple, 2001, 2004; Ball, 2006; Forsey, 2007; Karlsen, 2000; Kingfisher \& Maskovsky, 2008). The evidence from this study supports findings from these and other scholars that indicate that the rhetoric of autonomy, empowerment and decentralisation are the means by which governments re-centralise control and steer from a distance. The evidence demonstrates that control was recentralised by legitimising performance mechanisms, in the form of national testing. However there are indications that the focus on national tests may have alarming consequences for the content and context of education. I argue that the complexities of learning and fundamental pedagogies are being ignored, obscured and possibly even lost by an over-reliance on data systems that ignore or obscure these complexities in preference for a shallow and narrow set of standardised measures.

\section{The case study}

This ethnographic study was carried out, on a daily basis over a ten month period from 2008 to 2009, inside an Australian state Ministry of Education. The organisation, responsible for 780 public schools and more than 22,000 teachers, produced and mandated education policies, controlled funding to schools, and appointed and employed teaching staff. The states have traditionally had constitutional responsibility for education and despite increasing interest from Federal government over the last two decades Australian states remain constitutionally responsible for education (Lingard, Hayes, \& Mills, 2002). The problems, presented by the demographics of the vast continent, have resulted in Australia creating some of the most centralised bureaucratic systems in the world, a point worth noting, as it has particular relevance in this study (Lingard et al., 2002, p. 73).

Throughout the preceding decade this state bureaucratic organisation developed neo-liberal strategies comparable with Westernised education systems. At the end of the 1990s the state government introduced a curriculum framework which was mandatory for all schools throughout the state. At the same time a state literacy and numeracy test was introduced for students at years three, five, and seven, as the curriculum framework became established in the system. Literacy and numeracy resources in the form of books and teaching material were developed by the central organisation to provide support for the developmental curriculum that was similar in some ways to the key stages in the UK. Although the resources were effective, there was a demand from teachers for professional development that supported the literacy and numeracy resources. The professional development programs were developed, then administered and delivered by literacy and numeracy teams from the central organisation. It is the numeracy program that is the focus of this paper. 
I was given access to the section responsible for providing educational support to schools. This section was staffed by almost 200 people who all had backgrounds in education. Inside the organisation people were positive about my project and curious about participant observation. I spent ten months observing, listening, questioning, participating in formal and informal meetings, recording when appropriate, but relying on the notebook to make copious notes. A wide variety of documents were gathered and analysed. The long term engagement (Jeffrey \& Troman, 2004) allowed me to establish relationships with people at different levels of the hierarchy and gain an understanding of their perspective on the role of the organisation, their work, their ambitions, and their beliefs and values.

When I began this study, the organisation was about to be restructured in response to a document produced by the organisation and written by the head of the organisation, that proposed a focus on classroom practices. In the space permitted in this paper I am able only to state briefly the aims of the document which was central in the restructure of the organisation. The document specified a decentralisation of services and this had a direct effect on those working in the educational support section. No longer would they deliver services in the form of professional development programs. It was intended that they would instead focus on giving advice, help with planning strategies, and make resources accessible online for schools to access. I was allotted a desk in the open office space close to the numeracy team that delivered a professional development numeracy program to teachers to become numeracy specialists in their schools. During the ten month period that I spent inside the organisation the professional development literacy and numeracy programs were withdrawn, and the funding instead allocated to schools directly to allow them to become flexible and autonomous. I witnessed the dramatic change in the work of the numeracy team.

\section{The complexities and contradictions of neo-liberalism}

Over the last two decades the transition in public administration systems has affected public education systems globally. Clarke and Newman (1997, p. 22) argue that public administration has shifted toward a set of practices and values that is separate from the content and character of the services that are delivered. They suggest that there is no link between 'better efficiency' and the outcomes the organisation is trying to achieve and that better efficiency is often achieved by increased management and a decrease in the number of professionals. In education the transformation is reflected in the rhetoric of education policy and educational reforms that are bound to market forces and the strengthening of the economy and in the changing relationship between government, schools and parents (Whitty, 2002). Apple (2001) claims that the transformation of educational practices through the contestation of the means and ends of education by multiple voices is inherently political. These trends were evident in the restructure of this Australian state organisation.

The document that initiated the change in role of the organisation proposed to put classrooms first, support teachers, and promised to shift from a managerial focus towards stronger links with educational improvement. The ideology of neo-liberal rhetoric has a seductive appeal; the empowerment of the individual, autonomy, the ability to make 
choices, responsibility through decentralisation and the lure of excellence and success. Neo-liberal ideology is complex and often contradictory. Intimately bound and difficult to separate, the discourses create on the one hand, the enterprising autonomous teacher or school and, on the other, demand accountability, standards and target setting (Apple, 2001, p. 410). Sørensen argues that the use of overt strategies of decentralisation of services, autonomy, and empowerment, if skilfully employed, tend to strengthen rather than weaken bureaucratic forms of governing (2007, p. 108). Blackmore argues that decentralisation is a strategy that is used to shift education from a 'public investment for the common good' to a notion that education could position the individual competitively (2004, p. 268). According to Blackmore, decentralisation as such is not the problem the problem lies in the reforms that are associated with decentralisation that lead to the weakening of socio-cultural values through the focus on particular forms of accountability (2004, p. 284).

In a similar manner, Miller and Rose (2008, p. 36) argue that through an array of performance technologies these organisations maintain control and ensure that responsibility is taken by individual citizens by shifting the blame from the policy site to the site of implementation. At the time of this study, state-wide testing of students at year three, five and seven had been used by the public system for almost a decade and during the period of this study Federal government introduced testing at the national level for the first time. These were the performance technologies that determined the level of achievement of students and the ultimate success of individual schools. At every level, the plain speaking, commonsense discourses of neo-liberal rhetoric appeals to educationalists (Apple, 2001). Schools, teachers and students must also be accountable and control is legitimised by performance technologies that discipline (Ball, 2006; Mahony \& Hextall, 2000). However Ozga (2009) warns that not only has there been an increase in performance technologies, but the reliance on them has led to a fetish with data.

\section{The fetish with data}

Neo-liberal reforms have attempted to increase efficiency and effectiveness by debureaucratisation and privatisation through the promotion of new forms of administration and management. But at the same time what has also increased is the reliance on performance technologies controlled and monitored by the state. Over the past few decades centralised bureaucratic organisations which monitor, administer, and control education have developed creative performance technologies to measure standards in our schools and to make comparisons at national level, as well as between nations, in order to be competitive in global markets. The focus on standards and targets has led to the creation of new methods of evaluation and a demand for more information in the form of neutral, rational assessment. The combination of these demands has resulted in the teacher and pedagogy being 'treated as technical resources to be managed in the delivery of information to the knowledge economy' (Walsh, 2006, p. 101). Walsh asserts that the increased distrust of teachers has led to the subordination of their professional knowledge and judgment in preference for the 'measurement of performance' so that their critical voices have been increasingly silenced at policy level (2006, p. 112). I doubt that the 
voices of teachers were often heard at policy level, but I agree with Walsh that the teacher and pedagogy are increasingly treated as manageable technical resources. Teaching practices and learning are now tightly bound to a narrow assessment through performance technologies.

Performance technologies are increasingly tied to the growing data collection (Ozga, 2009). In general, developments in performance technologies have been 'understood as vehicles for improved policy-making and better-informed pedagogic school practices' (Grek, Lawn, Lingard, \& Varjo, 2009, p. 122). Most of us are familiar with the language of educational assessment: target-setting, standards, indicators, benchmarking, auditing, monitoring, and accountability. But what is being measured through the creation of national tests and the myriad of performance technologies? What is validated and whose values are they? These questions have been posed by many educational researchers concerned with the practices associated with developing learning strategies and pedagogies that equate with the reality of the classroom. Ball (2006, p. 148 ), in an analysis of performance technologies and mechanisms, asserts that we are wandering in 'the labyrinth of performativity.' In a recent article, Ozga (2009) notes, that the fetish of data has become the major focus for measuring the quality of education in the UK.

In European countries, Grek et al. (2009) argue that comparison between schools has become the factor which drives educational assessment. Although the quest for a competitive knowledge-driven community through the use of data can be traced back to the 1970s, in Europe, there was an increased interest in setting standards for education systems that began around the year 2000 (Grek et al., 2009, p. 127). Similar trends can be traced in Australian education. In 2008 the introduction of assessment by the Federal government nationwide brought all schools under the same performance technology. However the centralised system in this state provided interventions in the form of programs that were delivered by staff from the central organisation, the bureaucrats.

The following account is a summary of the data gathered over the first few months of my research period. The data comes from conversations and observation of the numeracy team as they worked together in the office, at presentations at workshops with teachers and on their visits to schools.

\section{Centralised interventions and changing teaching practices}

The numeracy resources were developed from evidence-based research by the numeracy team in cooperation with a group of skilful researchers at a local university at the end of the 1990s. The university researchers were interested in how children developed their mathematical learning, and the numeracy team were interested in developing a program that would provide support for teachers in teaching numeracy. The groups worked intensively together, using the classroom expertise of the team, who were all plucked from teaching posts throughout the state, combined with the research and analytical knowledge of the academics. On completion of the material, state teachers began requesting a professional development program that would train teachers to become specialists in numeracy which coincided with increasing interest in literacy and numeracy standards from the Federal government. The numeracy team were given new contracts 
and began to develop a professional development program delivered by the team at workshops and supported by follow up visits to schools. The central organisation used the information from the expanding data systems to evaluate which schools had large numbers of low achievers in literacy and/or numeracy. These schools were then allocated the funding to allow one of the classroom teachers to become a specialist. The numeracy program was just one of the centrally-run programs that was delivered to schools. Interventions are always extraneous and have, according to Lea (2008, p. 201), little relation to the realities of the situation and will have the effect of excluding rather than including. However my suspicion about the effectiveness of interventions such as the one described here were well and truly laid to rest when I experienced at first hand what the program 'did' and fully understood its significance.

When I began my study, the professional development numeracy program had been running for nearly a decade and over 500 specialists had been trained in literacy and numeracy throughout the state. The professional development program was delivered by the team in six 3-day workshops over a period of two years. Between workshops the team arranged to visit the school, coordinate with the specialist and the principal and provide support for the planning and teaching practices that were initiated through the program. It was the visits to schools and through conversations with teachers and principals that I became convinced that this program was not just another intervention as the following evidence will demonstrate.

\section{In defence of centralised programs}

The numeracy team was made up of four women, Lisa, Laura, Rachel and Deborah who were passionate about numeracy. From their work as maths teachers they had developed a deep knowledge and understanding of the way in which students learned maths strategies and of how teachers developed maths skills.

Rachel, the most recent member of the team, had worked as a specialist in a school and had been head-hunted to the team. Her current experience of classroom teaching and of working effectively with other teachers meant that she was a significant addition to the team. The team were proud to have her recent classroom experience to draw on and any lack of knowledge she may have had was made up by the confidence in her current classroom experience. She told me that schools were confident in the program; 'it was well researched, well constructed' and it was 'central and everybody got the same message'. Lisa, Laura and Deborah were old hands having been involved in the initial development of the program. Lisa and Deborah focused on primary schools while Laura had sole responsibility for working with secondary teachers.

Lisa fondly remembered the intense innovative work that went into working out how students understood mathematical strategies. She expressed her belief in the power of the program in this way:

It is a feeling that you can produce change in a fairly major way through the ST (specialist teacher), because the ST is then going to have all those teachers coming past them. So you think about that degree of change that you can achieve! 
Lisa reflected first on being part of the team and on the strength of being in the bureaucratic organisation where there was 'a clear idea of its professional development,' and 'professional idea of what we want teachers to learn', and 'being a central initiative, where you have the same message going out to everyone'. The power of the programs was in being able to reflect, adjust and respond to the practices of the classroom. Each member of the team talked about the importance of maintaining an ongoing relationship with schools, understanding the problems and the diversity of teacher experience and students capabilities. Their work was intense, the relationships strong, and learning was continuous.

Laura, who worked with secondary maths teachers, talked about the autonomy that the team enjoyed and the professional role that they took in adjusting the program. They were respectful of each other's knowledge and expertise and understood the need to build up close relationships with teachers and principals in schools throughout the state. Their conversations were about learning strategies and about 'effective' pedagogy. The program was under continual development by the numeracy team who used professional judgment and reflection to adjust the programs to the needs of the students and the skills of the teachers. By giving teachers pedagogical strategies that related to the development of mathematical learning in their students, combined with supportive assessment strategies developed by the team, the teachers were able to change their teaching practices in a supportive professional environment. In a state of this size, centralised initiatives were a common strategy for allocating resources.

The strength of the program lay primarily in the ability of the team to establish strong relationships with the specialist during training workshops and with the principal on the follow up visits to the schools. I accompanied the team on these visits. In one conversation with a teacher, she told me that if she had not become involved in the program, she would have been burnt out long ago, and would have left teaching. She found it the 'most useful pedagogical tool ever'. Other teachers also talked about the program giving them a new lease of life. It motivated them to teach and gave them a stronger sense of commitment. They had observed how students began to work mathematically and became motivated and interested, as I also had. The energy and engagement that the specialists experienced in the classrooms became the focal point of the workshop sessions. There was exchange of experiences, of strategies, of what worked, where, with whom, and how. The teachers talked about 'a big learning journey', one said, 'I really believe this will make a difference to student self-esteem, increasing confidence in maths enjoyment and engagement'. The enthusiasm for the work done by the team was evident in other comments that the team provided 'great resources' and were 'excellent presenters'.

It is important to remember that the comments came from teachers in schools where both the students and teachers were struggling to cope. What the program presented was not just the developmental strategies for learning numeracy but also a wide range of pedagogical tools that could be adjusted to the disparate groups. One principal told me that the program 'was the best strategy that we have ever experienced in terms of making a difference'. No matter who I talked to, they were certain that the program provided useful pedagogical tools and provided real support to the development of the students' learning. 
After four years the organisation requested an independent review of the program which was carried out by the Australian Council for Educational Research (ACER). The review leaves the reader in no doubt that the programs were indeed effective and that teachers as a result re-assessed their teaching practices, making them more explicit and more purposeful. The program was labelled 'successful' and allowed to continue in the same form with the numeracy team working professionally to continually adjust and develop it. The numeracy program was grounded in evidence-based research and encompassed the complexities of learning numeracy skills and diverse pedagogies and really did seem to work.

\section{Transforming rhetoric to practice}

It was therefore paradoxical that the document that was central to the restructure of the organisation stipulated a focus on classroom practices and suggested a need for explicit teaching practices and strengthening of teacher quality through choice of the appropriate form of support, the same aims of the professional development programs. However the document also stated that the centralised services, previously provided by the organisation, would be withdrawn and the funding allocated directly to schools. In this way, state schools would be empowered to be autonomous and flexible. As a result the organisation had to be restructured and chaos ensued as people struggled to understand the new role of the bureaucracy. The organisation subtly shifted from a professional organisation that led change to an organisation that focused on managing change processes. The numeracy team in particular were frustrated by the decision to abandon the program. In the confusion and chaos that resulted from the restructure of the organisation the work of the numeracy team gradually changed. No longer able to deliver workshops and visit schools, they were 'stuck in the office' (Lisa), putting resources online and giving advice by email about issues connected with numeracy.

At this time national testing was introduced by Federal government. Each member of the numeracy team was critical of the scope and breadth of a national numeracy test. The team were invited to meetings where the test items were discussed. In the preparation for these meetings I observed that the numeracy team noted that the wording was confusing, complicated, and ambiguous. They expressed their concern about the limitations brought by having only 30 items that meant that not all the topic areas could be covered adequately. The test was tendered out to item writers who were paid to come up with a series of items for each test year group. Lisa and Laura agreed that it was difficult, although not impossible, to write questions that tested the student at different levels of difficulty. They explained that it was necessary to ensure that different types of questions that tested recall, application and the ability to solve problems were included. Each member of the team was deeply concerned about the poor quality and low standard of the items in the test. However they were only asked for their advice regarding the quality and standard of the test and had no influence over its content.

\section{Teaching for the test}


As the new school year approached, the head of the organisation, backed by a media announcement by the Minister for Education, promised that all schools would shortly be able to access a ten week plan that would help them prepare their students for the national test in May. In the days and weeks following the announcement I observed how the rhetoric around the preparation for the test subtly changed from providing students with test skills, to what teachers need to teach for the students to achieve good results in the test. A short time after the announcement Laura became heavily involved in designing the plan, although this was more by default than good management. It had been decided that the teachers, over a ten week period, were to be provided with an online plan that described week for week what they needed to teach. The person asked to do the planning for online numeracy resource, had been unable to complete the ten week plan, it had been 'too big a project' and now Laura had been asked to take over the plan, such as it was. It was too late in the day to make major changes to the plan. Normally calm and considered, Laura's frustration was clear and she was muttering under her breath. I was curious to know what exactly she had been asked to do.

Laura explained that the four topics; number, space, chance and data, and measurement, had to be covered in the ten week period. It had been decided that every teacher should spend ten minutes every day developing skills that would be needed in the test. Weeks one and two were to be used for general preparation for sitting the test and reading and answering questions. From week three there would be a focus on essential skills in all four areas. A total of ten minutes each day should be given to each skill over the week with all skills over the four areas being covered progressively. Laura was hunting for good examples of questions from previous (state) tests that demonstrated the skills being taught at that level. The questions chosen by the other person were sometimes bad examples and were wrongly ordered in terms of difficulty. She was struggling to find the right material, with the deadline just 24 hours away. Laura was exasperated and said 'it is not educationally sound' and commented that if the starting point for the teaching was the question then 'the teacher will be teaching to the test'. The 'teaching' will only 'work with the students who have already learned these skills and therefore it is a waste of time for those students. The students who cannot answer the question will not be able to understand the process if they start with the question - therefore it is a waste of time for those students too'. The other danger, she confided, is that you are 'telling the teachers that this is all you need to teach. Your students are prepared for the national test, so what will happen to the rest of the year? What kind of signal is sent by a resource written like this?'

As I completed my research period I realised that many participants had left the organisation. Three out of the four members of the numeracy team had sought employment outside the organisation their deep knowledge and expertise lost.

\section{Conclusion}

The evidence from this case study of an Australian Ministry of Education demonstrates that centralised systems can create interventions that work. The public schools in this state were reliant on the organisation to deliver services in the form of programs that were centrally developed and centrally run. The power of the programs lay in the evidence- 
based research and knowledge of the complexity of learning. Making the move to decentralise services severed the strong links between the organisation and schools and caused a great deal of concern particularly at the level where the programs had been developed and delivered. The restructure and decentralisation of services to schools was presented as an attempt to empower them and make them autonomous. However the vulnerable schools, those with inexperienced teachers, weak leadership, and a majority of low achieving students did not have the internal resources to effect changes in teaching practices.

The evidence in this study supports Karlsen's claim (2000, p. 529) that decentralisation is a political tool of governance and that there is no shift of power to local level; in fact, all that was being transferred were the conflicts and problems. Although the restructure document proposed to support explicit teaching practices, and develop quality teachers, both strategies provided by the numeracy program, the programs were abandoned. It appears that there was a lack of knowledge inside the organisation about the content of the programs and the expertise of the people who had developed them was under-valued or simply ignored. What was valorised instead was knowledge based on a different set of values. The over-reliance on information systems to provide performance data is worrying, particularly as the evidence from this study supports the suggestion that performance technologies such as national testing appear to be based on a shallow set of standardised values that narrow the content and context of education (Ozga, 2009).

In addition the evidence presented in this paper suggests that the fundamental elements of education: the effective pedagogies, the complexities of learning, and the understanding of the development of the child, are subordinated or lost through the performance technologies of the contemporary educational landscape. This study presents the opportunity for a deeper understanding of the processes of change in the bureaucratic administration of educational practices. Acknowledging and going beyond the usual critiques of decentralised centralisation - withdrawal of responsibility by governments who are steering at a distance, failure to resource the rhetoric associated with decentralisation and autonomy, the increased monitoring that results from accountability mechanisms, and so on - this study suggest that there are valuable and effective educational practices being lost that are collectively focused, systemically produced and hence deeply unfashionable, and which are deemed incompatible with a neo-liberalist commitment to autonomy and competitiveness.

\section{References}

Apple, M. (2001). Comparing neo-liberal projects and inequality in education. Comparative Education 37(4), 409-423.

Apple, M. (2004). Creating difference: Neo-liberalism, neo-conservatism and the politics of educational reform. Educational Policy, 18(1), 12-44.

Ball, S. (2006). Education policy and social class. Oxon: Routledge.

Blackmore, J. (2004). Restructuring educational leadership in changing contexts: A local/global account of restructuring in Australia. Journal of Education Change, 5,3 267-288.

Clarke, J., \& Newman, J. (1997). The managerial state. London Sage Publications Ltd. 
du Gay, P. (2005). The values of bureaucracy: An introduction. In P. du Gay (Ed.), The values of bureaucracy (pp. 1-13). Oxford: Oxford University Press.

Forsey, M. (2007). Challenging the system? A dramatic tale of neoliberal reform in an Australian High School. Charlotte NC Information Age Publishing Inc.

Grek, S., Lawn, M., Lingard, B., \& Varjo, J. (2009). North by northwest: Quality assurance and evaluation processes in European education. Journal of Education Policy, 24(2), 121-133.

Jeffrey, B., \& Troman, G. (2004). Time for ethnography. British Educational Research Journal, 30(4), 535-548.

Karlsen, G. (2000). Decentralised centralism: Framework for a better understanding of governance in a field of education Journal of Educational Policy, 15(5), 525-538.

Kingfisher, C., \& Maskovsky, J. (2008). The limits of neoliberalism. Critique of Anthropology, 28(2), 115126.

Lea, T. (2008). Bureaucrats and bleeding hearts: Indigenous health in Northern Australia. Sydney University of New South Wales Press Ltd.

Lingard, B., Hayes, D., \& Mills, M. (2002). Developments in school based management: The specific case of Queensland, Australia. Journal of Educational Administration, 40(1), 6-30.

Mahony, P., \& Hextall, I. (2000). Reconstructing teaching: Standards, performance and accountability. London: RoutledgeFalmer

Marquand, D. (2004). Decline of the public. Cambridge: Polity Press.

Miller, P., \& Rose, N. (2008). Governing the present. Cambridge: Polity Press.

Osborne, D., \& Gaebler, T. (1993). Reinventing government: How the entrepreneurial spirit is transforming the public sector. New York: Plume Books.

Ozga, J. (2009). Governing education through data in England: From regulation to self-evaluation. Journal of Education Policy, 24(2), 149-162.

Sørensen, E. (2007). Public administration as metagovernance. In G. Gjelstrup \& E. Sørensen (Eds.), Public administration in transition: Theory, practice, and methodology (pp. 107-126). Copenhagen: DJØF Publishing.

Walsh, P. (2006). Narrowed horizons and the impoverishment of educational discourse: Teaching, learning and performing under the new educational bureaucracies. Journal of Education Policy 21(1), 95117.

Whitty, G. (2002). Making sense of education policy: Studies in the sociology and politics of education. London Sage Publications. 